\title{
A CIDADE DO PORTO NA PÁGINA E NO ÉCRAN
}

\author{
Maria Theresa Abelha Alves*
}

A cidade favorece a arte, é a própria arte, Lewis Mumford

Acreditando que a cidade favorece a arte e em arte se constitui, quando o Porto foi a "Capital Européia da Cultura», em 2001, dois artistas portuenses, o cineasta Manoel de Oliveira e o escritor Mário Cláudio dela forneceram um retrato artístico e que também se reconhece como um tributo à cidade, um tributo ao passado, um tributo à vida e, principalmente, um tributo à arte, a todas as artes que, ao longo do tempo, a edificaram e a celebraram. O cineasta, que já em outras ocasiões, tão bem soubera falar por imagens da urbe nortenha, de seu povo, de seus enredos de paixões e de sua faina foi convidado pelo produtor Paulo Branco a fazer um documentário sobre o Porto para celebrar o evento cultural. Da encomenda feita a ele nasceu o filme Porto da minha infância. Manoel de Oliveira julgou mais conveniente regressar ao tempo da infância e da adolescência para conferir sentidos a «seu» Porto, uma vez que, dada a condição de canteiro de obras em que a cidade estava mergulhada para atender às demandas de capital cultural, realizar um documentário naquele tempo era quase impossível. Assim é que, com retalhos de memória, a cidade é dada a ver, mas retalhos de memória que se constroem por meio de outros retalhos: obras artísticas de escultura, de arquitetura, de pintura, de poesia, de teatro, de música, fotografias de época e, principalmente, de cinema, esta impura «sétima arte» que se faz a partir de todas as demais.

Também o belíssimo livro Meu Porto, em cujas páginas se reproduzem as artes que a cidade favoreceu e as artes que a favoreceram, sejam literárias, picturais, arquitetônicas, gastronômicas ou cinematográficas deveu-se a uma encomenda feita ao escritor Mário Cláudio para celebrar a mesma efeméride cultural. A pessoal leitura da cidade feita pelo escritor, que o torna capaz de apossar-se da urbe, transformando-a num produto particular designado pelo possessivo "Meu», é também ela, tal como a do filme de Manoel de Oliveira, um tributo artístico à urbe do Norte, porque, como se sabe, a página literária promove um cruzamento de saberes, é território sempre limítrofe, propício aos «contrabandos» culturais.

Declaradamente, o Porto consiste num objeto de amor para os dois artistas. Eles nasceram e vivem no Porto, ambos traduziram a cidade incontáveis vezes em

* Professora Doutora, Pesquisadora do CNPq, docente de programas de pós-graduação da Universidade Federal do Rio de Janeiro e da Universidade Estadual de Feira de Santana. Autora de livros e artigos sobre Literatura Portuguesa publicados no Brasil e no exterior. 
suas respectivas obras. Apesar de já ter escrito tantas vezes sobre o Porto, pano de fundo de muitos romances e assunto de crônicas, Mário Cláudio confessa experimentar «a dourada permanência de uma intangibilidade» (p. 11) a cada nova tentativa de definir e traduzir a cidade, afirmando: «Não há cidade como o Porto que não permaneça página em branco ao cabo de linhas e linhas escritas» (p. 11). Se muitas vezes ele foi solicitado por outros ou por si mesmo a escrever sobre ela, experimentou uma sensação de impotência, confessando: «Vezes sem conta julguei ter esgotado o assunto, vezes sem conta emergi de mãos vazias, sem um adjectivo a que pudesse apegar-me» (p. 11), isso porque em cada cidade há sempre mais do que a vista alcança, há sempre mais sons do que o ouvido pode ouvir e há sempre um novo cenário em contínua e mutável sucessão de imagens à espera da análise. Talvez essa mesma solicitação vital e esta mesma impotência tenha acompanhado o cineasta, impelindo-o a fixar a geografia física e social do Porto desde as tomadas extraordinárias de seu primeiro documentário, Douro Faina Fluvial, de seu primeiro filme de ficção, Aniki Bobó, e outros mais, o que valeu à cidade ser, por obra de Manoel de Oliveira, dentre todas as urbes portuguesas, a que mais foi filmada. De ambos os artistas poderiam ser as palavras do escritor: «O Porto nasce e morre conosco, igual ao mais insatisfeito de quantos desejos nos visitaram» (p. 11). Esse desejo sempre por realizar dinamiza as duas obras que trouxemos a este colóquio, cenário de trânsitos intersemióticos.

O Porto de Mário Cláudio em alguns aspectos se assemelha ao de Manoel de Oliveira: para um e outro a cidade consiste num cofre de lembranças, onde bem guardados ficaram monumentos, artistas, vultos históricos, prazeres e saberes, constituindo-se tudo isto no ouro dos dias da urbe. Ambos contrapõem lembranças passadas a experiências presentes. Ambos leem sua cidade segundo o corpo da memória coletiva e segundo a memória do corpo individual, selecionando-as, organizando-as e dotando-as de sentido, num processo de constante interação entre o desejo, o fato e o sonho. Ambos vivenciam a cidade do Porto dialeticamente entre a cidade ideal e a real, quantitativa e qualitativamente apreciadas segundo as diversas temporalidades que a cidade abarca, segundo a dinâmica dos diversos agentes sociais que a cidade congrega ou segrega. Ambos compreendem a sua metrópole como ponto de convergência da arte e da história, por isso citam artistas e visitam os monumentos, considerando uns e outros como mirabilia urbis que do passado magnificam o presente.

A banda sonora do filme, desde a apresentação dos créditos, recorre à música, como se fosse a ouverture de uma ópera que, desde o início, apresenta seus principais temas. Duas melodias compõem essa ouverture: uma é cantada em off; outra é apenas instrumental. Trata-se, a primeira, do poema de Guerra Junqueiro, «Regresso ao lar», que foi musicado como um acalanto, já a outra é um fado muito conhecido, nos anos 1920, denominado «Fado das mãos». A primeira melodia atesta a nostalgia com que se tecem as visitas ao passado, a segunda, o gosto 
musical da época, porém a imagem com que o filme propriamente começa é a de um maestro. Ele rege uma orquestra que executa a obra Nachtmusik I, do compositor português Emmanuel Nunes, música que evidencia, por seus acordes dissonantes, um compromisso com a contemporaneidade (fig. 1). Essa música é uma serenata, como a Nachtmusik número 13, de Mozart, para cordas em sol maior, mais conhecida por «Eine Kleine Nachtmusik». Se do hoje o compositor contemporâneo fizera uma homenagem ao compositor do passado, o filme, através das músicas citadas, demonstra que a partir do presente ilustra o passado, ao mesmo tempo em que tece um elogio à arte da música, em suas mais diversas manifestações. O maestro é um homem de sala de espetáculos, dos grandes teatros de ópera que sempre seduziram o cineasta. É o condutor do compasso e, por isso mesmo, do tempo. É esse investimento no tempo que a imagem visa registrar, como a insinuar que somente a arte é capaz de perenizar o instante, pois só ela permite confrontar, afrontar e subverter a inexorável corrosão de seres, coisas, tudo, provocada pela devastadora ação de Cronos. E é o tempo da infância e da adolescência pessoal do realizador que o filme resgata, uma espécie de regresso ao lar antigo, como sugerido pelo poema de Guerra Junqueiro que se ouve, na íntegra, cantado como um acalanto, na bela voz da esposa do cineasta. Além de uma pessoal história, a película fornece também a história coletiva do burgo e atrelada a uma e a outra, uma terceira história emerge: a da arte.

Embora o livro de Mário Cláudio não objetive a infância do escritor, de incursões ao passado e também a algumas lembranças infanto-juvenis ele se tece e as memórias pessoais são igualmente vias de acesso à história da cidade e do indivíduo, como história da arte. Assim o escritor e o cineasta estabelecem uma relação dialética com a cidade de modo que a representação histórica externa, que repousa na consistência factual, se encontre e se imbrique com a história interna, que só adquire significados a partir da consciência individual que transmite valor a fatos históricos e a objetos artísticos, construindo, cada qual a seu modo, uma pessoal cidade, uma pessoal história, um pessoal museu e uma pessoal biblioteca.

Uma das primeiras memórias do cineasta é precisamente a do camarote do teatro onde assistira à ópera Carmen e os acordes da famosa «Canção do Toureador» lhe ficaram para sempre na lembrança. Mário Cláudio, também um apreciador da música operística, à sua maneira também a ela alude, no retrato que dá de seu Porto, pois suspeita que «haveria de agradar a Wagner a ideia de que por esta paisagem [a do Porto] teriam estanciado os Nibelungos» (p. 15). Se a primeira parte da tetralogia com que o compositor alemão traduziu a lenda dos Nibelungos, Das Rheingold, focaliza o ouro do Reno, a alusão a Wagner é feita, precisamente, no capítulo inicial do livro, intitulado «Pátria Mátria» e que se faz anteceder da reprodução de um quadro de Joaquim Lopes, Barcos à descarga no Rio Douro que, aludindo ao ouro não do Reno, mas deste outro rio, é uma marinha em que diferentes nuances do amarelo aurífero se contaminam na formação da mancha 
pictórica. Aliás, o ouro do Douro se inscreve no livro de Mário Cláudio desde o início do livro que, mesmo antes da ficha catalográfica, dá a ver uma imagem que ocupa duas páginas, reprodução do óleo Rio Douro, de Manuel Maria Lúcio. Nessa pintura, o rio que banha a cidade contamina com seu curso dourado as casas marginais que também foram compostas por anilinas amarelas. Assim como o Reno da saga nórdica guardava o precioso metal, é um tesouro segredado que o livro busca encontrar, ouro já agora metafórico: o que da paleta de seus pintores nasce, pois do mesmo ouro do Douro se pinta o casario da famosa rua, no próximo quadro reproduzido, Rua da Lada, de José Maria Soares Lopes, é o mesmo ouro que lança uma profusão de nuanças douradas sobre verdes tons primaveris, no seguinte quadro, Manhã de Primavera, ainda de Joaquim Lopes, e ainda é o mesmo ouro que torna clara a Rua Escura, de José Campos, última reprodução deste capítulo inicial. Como Alberich, que na ópera de Wagner é quem rouba o anel dos Nibelungos, o escritor da cidade, juntamente com os pintores que a fixaram em tela e cores, são «ladrões» dos tesouros escondidos desse outro rio. Eles o roubam para tornarem-no conhecido, ouro dessa outra hiperbórea cidade, já agora do norte de Portugal. A alusão a Wagner ainda repercute ao longo deste início: se são os gigantes que erguem o castelo de Wotan, são «as magnas figuras autóctones, sobretudo as que se implantam no já de si nevoento tabuleiro das artes e das letras» (p. 15) as que erigem este outro castelo: a cidade do Porto como tal. Assim o lento prelúdio com que Das Reingold começa e que representa o movimento do Reno, parece contaminar com seus acordes o prelúdio de Meu Porto, obra que sintomaticamente se faz iniciar com o rio e acaba por referenciar seus gigantes: os artistas engrandecidos pelo valor atribuído a suas obras.

O cronista da urbe alude em Meu Porto aos escritores como «magnas figuras», citando Almeida Garrett, Júlio Dinis, Camilo Castelo Branco, Antonio Nobre, Raul Brandão, Ramalho Ortigão, Arnaldo Gama. De alguma forma, eles ajudaram a construir a imagem da cidade, ora como criadores de enredos, ora como personagens urbanos, pois uma cidade se edifica também pelos livros. Estes escritores que leram e deram a ler a cidade são os que figuram em Porto da minha infância, pelas lombadas de seus respectivos livros, dadas a ver no final do filme, quando a câmara, num sugestivo travelling, por elas passeia, como se quisesse advertir que foram aqueles escritores e aqueles livros que deram à cidade sua versão mais apurada (fig. 2).

As cidades guardam histórias, as cidades guardam a arte. Embora esta se proponha a cada um no presente absoluto da apreciação, ela é capaz de tornar contemporâneas antigas histórias, acionando o movimento interior que consiste em imagens concretas suscitarem lembranças pessoais ou coletivas encasteladas no passado. O filme de Manoel de Oliveira é todo construído a partir deste processo. O cineasta, por exemplo, enquadra a estátua de Almeida Garrett, após ter enquadrado a de D. Pedro IV e assim, por meio dos dois monumentos, esculturas 
presentes a seus olhos, celebra as res gestae do passado e a vocação libertária do Porto, mas celebra também a poesia de Garrett, ao fazer as imagens serem acompanhadas de um poema lírico de Folhas Caídas. De igual modo, este acontecimento histórico é por Mário Cláudio também recordado a partir do poeta romântico, quando retoricamente pergunta: «Pois não é verdade que percorreu Almeida Garrett, experimentados os fumos das canhonadas do Cerco, um cenário de saudades pungidas e de encobertos regressados de Alcácer Quibir?» (p. 15). E de Dom Pedro também fornece um simpático retrato, ao relembrá-lo a irromper pela cidade, «Em nove de Junho de mil oitocentos e trinta e dois, [...], comandando tropas entusiásticas, e de fuzil enfeitado pelo azul-sulfato das hidrângeas com que iam topando na beira dos caminhos» (p. 99). Manoel de Oliveira parte das estátuas gigantescas do poeta e do rei, ícones citadinos, e nelas encontra um referencial que lhe possibilita falar de poesia e deixar a poesia a si mesma falar, valorizando assim o acontecimento histórico e concedendo ao fato o atributo poético do sonho libertário. De igual modo, Mário Cláudio relembra poeticamente o episódio histórico da cidade, concedendo-lhe a concretização de uma quimera, ao vislumbrar, no exército esfarrapado de que Garrett fizera parte, regressados de Alcácer-Quibir: concretização de um sonho antigo e sempre alimentado pelo imaginário português. Almeida Garrett, poeta nomeado, torna-se então metonímia de outros poetas anônimos, aqueles que com a delicadeza própria dos artistas camuflaram em beleza suas armas ao enfeitarem-nas com as flores recolhidas no caminho, substituindo-lhes o caráter mortífero pelo anúncio azul da vida e da liberdade. Tal metamorfose, entretanto, só se dá no universo poético da página, pela visão transfiguradora do cronista de Meu Porto.

Em Porto da minha infância, Manoel de Oliveira refere-se a muitos pintores que juntamente com ele e outros artistas faziam parte de uma juventude mal vista pelo Regime de Salazar. Esta juventude continuava o sonho libertário do exército de Dom Pedro IV, incrustando suas armas de combate - as telas cobertas de tinta, os projetos de filmes, ou o pensamento verdadeiramente humanista - com a mesma poesia das hidrângeas azul-sulfato. Eram eles considerados nefastos ao Poder de então porque esta abstrata entidade ou reconhecia o papel subversivo das múltiplas cores naquele tempo absolutamente cinzento, ou temia que jovens de ideias e ideais viessem contaminar com sangue novo a anemia conservadora daquele tempo. O nome deles, principalmente o dos pintores, é relembrado pelo cineasta daquela mesma geração. Mário Cláudio, por sua vez, ilustra o livro Meu Porto com reproduções de pinturas de artistas que souberam declinar suas anilinas convertendo-as em tradução da luz e da névoa que caracterizam a cidade, transformando em imagem a condição granítica da cidade, sua «solidez de uma cidade pétrea»(p. 16). Alguns daqueles citados pintores mal vistos pelo Regime, como Dominguez Alvarez, ilustram com seus quadros o Porto de Mário Cláudio, tendo seus nomes registrados ao lado das ilustrações. Outro dos mal vistos, como ocorre 
com Ângelo de Sousa, é nomeado no texto, quando Mário Cláudio se refere ao mais conhecido e popular bairro da cidade, porque no seu universo pictórico, a Ribeira «permaneceria intacta nos óleos esplêndidos» (p. 29), capazes de revelar, na absorção dos pigmentos, sua granítica condição. Tal característica pétrea da cidade é também sublinhada pelo cineasta quando se lembra dos pedreiros que a ajudaram a edificar-se, pois que no tempo de infância daquele que viria a ser o maior realizador português, todas as casas eram de pedra. Ao mesmo tempo lhe dá a oportunidade de passear sua filmadora pela estátua de um pedreiro, fixando-lhe as mãos num sugestivo insert a fim de ratificar que todo pedreiro é faber, um artista da mão (fig. 3).

Em Porto da minha infância o cineasta alude aos espetáculos teatrais a que assistira na infância. Um deles foi a opereta Miss Diabo. A cena que na altura mais impressionara o menino - a do ladrão a adentrar a casa - é ele mesmo, já agora ancião, que, como ator, a representa no filme (fig. 4). O menino do passado é relembrado, pelo cineasta de agora, findo este espetáculo, a mergulhar em seu Porto descendo as ruas da cidade velha no automóvel da família. Mais tarde, quando já um boêmio rapaz, relembra que descia a pé as mesmas ruas, em companhia dos amigos escritores Adolfo Casais Monteiro e Rodrigo de Freitas e do ator amigo, António Silva. Os quatro, a descerem as ruelas da Ribeira, são a literatura, o teatro e o cinema conjugados. Em plongée se filmam tais recordações. De igual modo é que Mário Cláudio toma conhecimento da Ribeira: «A minha Ribeira mais antiga nascia de uma vista em plongée, dois ou três rabelos sobreviventes, arvorando a enorme vela da viagem lancinante, algumas barcaças de carvão» (p. 21). Este relato se aproxima de uma das tomadas do filme de Manoel de Oliveira, quando o cineasta com seus amigos descia uma das ruas da Ribeira, chegando ao Douro onde, através de imagens do primeiro filme do cineasta que foram enxertadas no filme comemorativo de 2001, veem dois rabelos singrando as durienses águas e também a barcaça de carvão sendo descarregada. Para recordar-se do Porto de sua infância, o cineasta inclui passagens de outros filmes seus, Douro faina fluvial, é um deles, mas é com a mesma imagem cinematográfica deste primeiro documentário de Manoel de Oliveira que Mário Cláudio diz de sua «Ribeira mais antiga», talvez porque seja impossível desvencilhar uma cidade de suas imagens cinematográficas.

A ideia de desterro está numa obra e na outra marcada pela estátua $O$ Desterrado, do escultor Soares dos Reis. Em Mário Cláudio a estátua é o pretexto para introduzir o fato de que muitos aldeões emigravam, condicionados pela pobreza. Em Manoel de Oliveira serve para focalizar o exílio dos intelectuais para o Brasil, em virtude do regime ditatorial de Salazar, o que acontecera com os portuenses Agostinho da Silva e Adolfo Casais Monteiro. O Desterrado, obra-prima da escultura portuguesa, comparece no livro e no filme pelo valor intrínseco de obra de arte que inegavelmente possui, comparece ainda como homenagem merecida ao escultor Soares dos Reis, tão injustiçado no tempo de feitura de sua obra 
magna, quando the recusaram a originalidade, o que o levou ao suicídio, e comparece também como ponto de partida para o questionamento de um fato histórico: o êxodo de muitos portugueses por perseguição política ou por questões econômicas, no século XX.

Se em Porto da minha infância, o cineasta recorre a filmes antigos para dar a ver os bondes que então circulavam pela cidade, fazendo de sua lembrança um tributo à arte cinematográfica, é com uma imagem similar que Mário Cláudio diz de sua infância, como se num daqueles elétricos fizesse um travelling pelas ruas do centro da cidade, encantado com o «emaranhado de rails que conduziam a outros rails, tudo a uma luz amarela de brinquedo perfeito» (p. 19), encontrando neste emaranhado oportunidade para render um tributo à literatura, referenciando o poeta Rilke que um dia escrevera, em Os cadernos de Malte Laurids, "carros eléctricos rolam tocando através do meu quarto» (p. 19).

No filme o passado muitas vezes se recupera pela montagem em que se aproveitaram fragmentos de antigas películas, do próprio cineasta ou de outros. Para ilustrar a lembrança de seu primeiro amor, a prima Guilhermina, morta prematuramente por uma tuberculose, Manoel de Oliveira recorre ao inocente idílio de Aniki-Bóbó, seu primeiro longa-metragem (fig. 5). A este filme Mário Cláudio se reporta para salientar a diferença entre a geografia humana da Ribeira dos dias de hoje e a do tempo de sua adolescência, observando que «Um realizador que se atrevesse nos dias de hoje a recontar as façanhas da trupe de AnikiBobó teria de alicerçar o seu enredo em figuras diversas, não nos ingênuos Carlitos e Teresinha» (p. 27), mas talvez os enamorados seriam: «uma rapariga vietnamita que vendesse relógios e um rapaz arrumador de automóveis, aventurando-se ambos [...] no roubo [...] e no consumo, de um pacotinho de ganza» (p. 29). Se o cineasta, na sequência em que introduz o Aniki-Bóbó no novo filme fazia uma observação social sob a doença que lhe roubara o primeiro amor, o escritor usa o mesmo filme para referir-se aos novos eczemas sociais. Através do tributo à arte cinematográfica, as maleitas urbanas se evidenciam. Não é apenas nessa passagem que o cineasta é referência do Porto de Mário Cláudio. Numa outra, o escritor se faz acompanhar por Camilo Castelo Branco num passeio pelas ruelas da cidade histórica, em demanda de Simão Botelho e Teresa de Albuquerque, mas as imagens, com que traça o roteiro de sua cidade até chegar ao convento de Monchique para relembrar a saga dos amantes de perdição, são as do filme de Manoel de Oliveira. E também, ao referir-se aos habitantes ingleses da cidade, sintetiza a estória de Fanny Owen e de José Augusto de Magalhães, que o cineasta já eternizara no magnífico Francisca: «enlouquece uma inglesinha, suicida-se um impotente» (p. 94). Manoel de Oliveira rende homenagem ao primeiro cineasta português: Paz dos Reis, também do Porto, inserindo parte do primeiro filme luso, ao relembrar a Rua de Santa Catarina de sua infância. Atribuindo ao cinema a «sorte de magia» de fazer o passado se tornar presente pelas 
imagens virtuais do cinema, traz de volta o primeiro cineasta para filmar a saída dos operários das obras do Porto Capital da Cultura, do mesmo ângulo que, no passado, filmara a saída das operárias da fábrica Confiança (fig. 6). A referência cinematográfica de Mário Cláudio já não é mais a do primeiro cineasta português, mas a do grande realizador, daí aludir aos filmes Aniki-Bóbó, Amor de Perdição e Francisca.

Para um e outro artista o Porto tem prazeres insuspeitados de cama e mesa. Ao referir-se à sua juventude boêmia, o cineasta relembra os clubes noturnos. Havia desde os mais luxuosos e bem frequentados até os mais simples, que eram o último recurso para encontrar uma rapariga disponível. No interior dos mesmos, pares dançavam ao som de um tango e jovens elegantes desfilavam paetês e boás. As mulheres elegantes que frequentavam tais clubes eram mantidas por homens mais velhos que lhes davam, como uma delas confessa, «muito conforto na vida», tratando-as cerimoniosamente por «senhora», mas, ao mesmo tempo considerando-as «pegas» (fig. 7). Para evidenciar o novo estatuto de tais acompanhantes femininas na sociedade moderna, num canto do clube, a escritora Agustina Bessa Luís, transformada pelo cineasta na personagem «Dama do Texto", lê uma crônica de sua autoria sobre a nova realidade das «gueixas» que já agora frequentam a universidade, são poliglotas e até leitoras de filosofia (fig. 8). Partindo da análise de um fato social, o cineasta rende homenagem à música, à dança e à literatura. A escrita de Mário Cláudio também visita tais casas noturnas, para traduzir o carpe diem da urbe, ou abrindo as portas de uma casa que relembra a Paris boêmia por onde mulheres de boá transitam enquanto recitam Baudelaire, ao som do tilintar de um serviço de Limoges, com isso demonstrando que «Não há espaço que outros espaços não abrace» (p. 19), ou observando que «Proliferavam os emblemáticos números das portas, largando uma memória honrada por sucessivas gerações, o noventa da Rua da Madeira, o quinhentos e quinze da Rua do Bonjardim, o cinquenta e nove da Rua dos Mártires da Liberdade» (p. 101). Tais casas continham «como peça nobre o amplo sofá onde se fazia sala, ou se aguardava que vagasse a menina escolhida» (p. 103). Ao referirem-se a tais casas noturnas, os dois artistas iluminam o lado obscuro e dionisíaco que constitui outro espaço cenográfico da cidade.

Se o cineasta expõe as confeitarias e cafés de seu tempo e as iguarias que lá se consumiam, Mário Cláudio também se reporta aos cozinhados de seu Porto e aos restaurantes e cafés onde se podia consumi-los. O certo é que para um e para outro, o Porto é objeto de amor e motivo de arte, por isso até a arte gastronômica é convidada para compor os hábitos da cidade, motivo para se perscrutar o interior dos luxuosos cafés e casas de chá dos tempos passados, falar da elegância dos figurinos das frequentadoras, como acontece no filme de Manoel de Oliveira, ou aludir às personalidades estrangeiras ou locais que se deliciaram com as iguarias portuenses, como acontece no livro de Mário Cláudio. 
O escritor e o cineasta têm consciência do próprio fazer artístico. Manoel de Oliveira depois de prestar sua homenagem urbana a poetas, escultores, arquitetos, pintores, atores, músicos, e autores teatrais, mostrando suas obras e desempenhos, a si mesmo exibe como artista, ou ao surpreender-se no Café Majestic a planejar uma obra que a censura não permitiu ser filmada, (fig. 9) ou em casa, à beira da mesa de bilhar, onde jaziam rolinhos de filmes à espera de seu momento de luz, a fazer manualmente a montagem de Douro faina fluvial (fig. 10), documentário que é um discurso cinematográfico apaixonado pela cidade, assim como Porto da minha infância também o é, já agora de uma forma requintada em que a apologia da urbe se faz como apologia à própria arte que a erigiu. De modo semelhante, Mário Cláudio dá a ler sua cidade, buscando-a em seus artistas, escritores, músicos, escultores, pintores, referindo-se a Manoel de Oliveira e, por conseguinte, ao cinema. Como o cineasta, o escritor também se autoreferencia em sua obra, quer trazendo para compor o macro texto poemas de sua própria autoria, como o dedicado a Tomás Antonio Gonzaga ou aquele outro dedicado à fundista Rosa Mota, quer aludindo a suas crônicas urbanas, como quando, ao nomear os pintores, diz que «uma crônica completa neles continha» (p. 29) referência implícita talvez à sua crônica «Três Livros» em que são considerados como livros da cidade as telas de Abel Salazar, António Cruz e Ângelo de Sousa.

$\mathrm{O}$ escritor e o cineasta, com arte e mediante as artes, trazem ao presente, na respectiva celebração do Porto, figuras do passado, rememorando fatos e lendas e dando-os outra vez e por ângulos novos à leitura, engendrando uma tipologia sensorial da cidade ao apreciarem-na histórica, sociológica e, sobretudo, artisticamente. Referenciam artistas para com eles e a partir deles traduzirem, cada um com sua respectiva arte, as ambiguidades de uma boa parte da história cultural e passional da cidade do Porto, não só como matéria literária, mas também como experiência de vida, confirmando que, de fato, "A cidade favorece a arte, é a própria arte» que, sensualissimamente, se oferta com saber e sabor, na saudade que persiste, no sonho por cumprir, no adjetivo por achar, ou na fantasia diária daqueles que declinam seu olhar sobre ela, tomando-a como objeto inteiramente pessoal, que só se nomeia pelos possessivos «meu» e «minha».

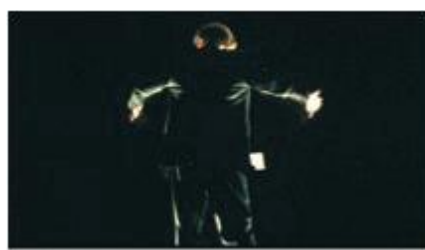

Fig. 1

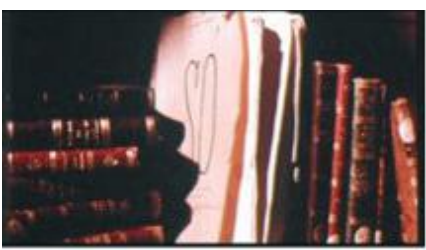

Fig. 2 


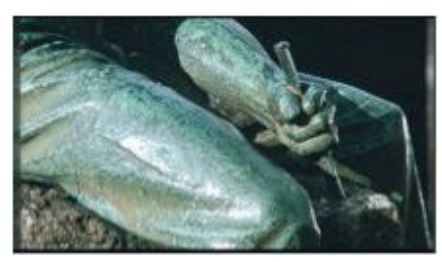

Fig. 3

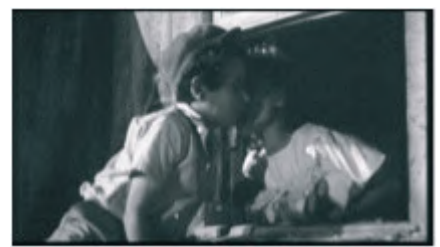

Fig. 5

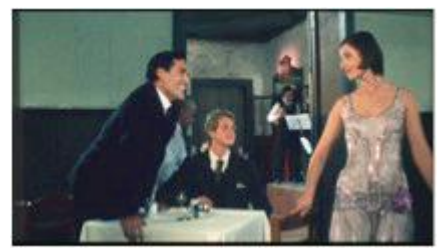

Fig. 7

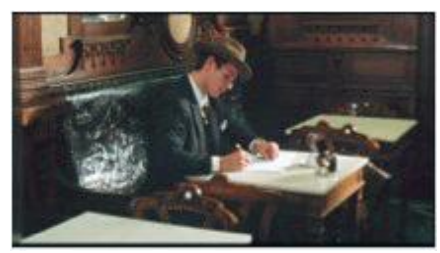

Fig. 9

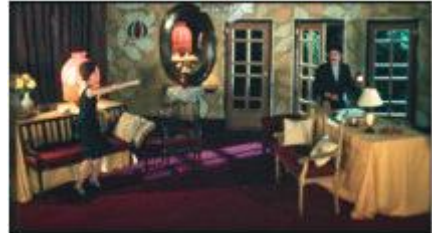

Fig. 4

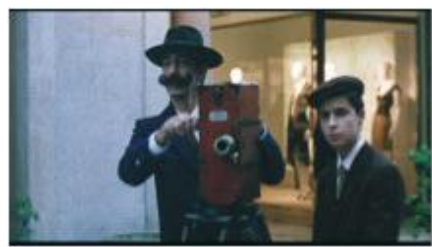

Fig. 6

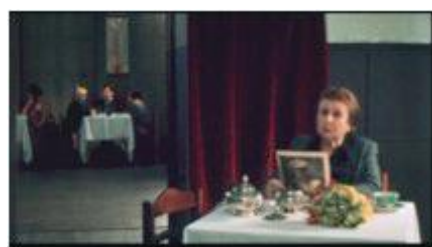

Fig. 8

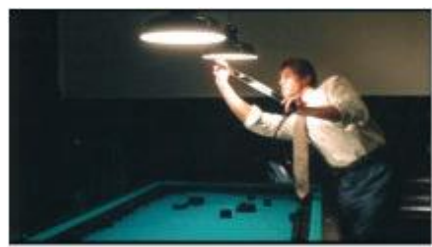

Fig. 10 
Resumo: A cidade e a arte que a constitui em duas obras: Meu Porto, de Mário Cláudio e Porto da Minha Infância, de Manoel de Oliveira. A memória na reconstrução dos quadros, das figuras e da história da cidade. Os contrabandos artísticos efetuados pelo escritor e pelo cineasta na construção que cada um faz de seu respectivo Porto.

Palavras-chave: Cinema e literatura, Representação da cidade, Memória.
Abstract: The city and the art that is in two works: My Oporto, by Mário Cláudio and Oporto of my childhood, by Manoel de Oliveira. The memory in the reconstruction of urban landscapes, iconic personalities, the plots and the city's history. The artistic contraband made by writer and filmmaker in construction that each makes their respective Oporto.

Keyworks: Cinema and literature, Representing the city, Memory.

\section{REFERÊNCIAS BIBLIOGRÁFICAS:}

Argan, Giulio Carlo. História da arte como história da cidade. São Paulo: Martins Fontes, 1992.

Cláudio, Mário. Meu Porto. Lisboa: Dom Quixote, 2001.

- Uma coroa de navios (seleção de Laura Castro). Lisboa: Dom Quixote, 1992.

LYNCH, Kevin. A imagem da cidade. Lisboa: Edições 70, 1999.

Mumford, Lewis. A cidade na história - suas origens, transformações e perspectivas. São Paulo: Martins Fontes, 1998.

OliveirA, Manoel. Porto da minha infância. Lusomundo Audiovisuais S.A. DVD vídeo, 2001. 
metamorfoses_12.1_Layout 1 12/20/13 4:42 PM Page 36- 